\title{
Heterogeneous LPS of Porphyromonas gingivalis differentially modulate the innate immune response of human gingiva
}

\author{
TDK Herath $^{1 *}$, Y Wang ${ }^{1}$, CJ Seneviratne ${ }^{1}$, RP Darveau ${ }^{2}$, CY Wang ${ }^{3}$, LJ Jin ${ }^{1}$ \\ From Institut Pasteur International Network Annual Scientific Meeting \\ Hong Kong. 22-23 November 2010
}

\section{Objective}

Porphyromonas gingivalis lipopolysaccharide (PgLPS) is a crucial virulence factor strongly involved in chronic periodontitis. PgLPS is known to contain both tetra- (Pg LPS1435) and penta-acylated (PgLPS 1690) lipid A structures with opposing effects. Present study aimed to examine the effect of two Pg LPS isoforms on human gingival epithelium.

\section{Methods}

Reconstituted human gingival epithelia (RHGE) were challenged with two isoforms of PgLPS together with $E$. coli LPS as the positive control. mRNA and proteins were harvested from tissues and culture supernatants were collected. Expression of pro-inflammatory and antiinflammatory cytokines was evaluated by Q-PCR and ELISA. Involvement of pattern recognition receptors and signaling pathways were also analyzed by Q-PCR and western blot. Next, RHGE was blocked for CD14, TLR2, and TLR4 and followed by stimulation of PgLPS isoforms and effect was evaluated at cytokine level by Q-PCR and ELISA. Furthermore, we used "tissue proteomics" approach to study the differential proteomic expression profiles of gingival epithelium upon Pg LPS stimulation.

\section{Results}

It was shown that penta-acylated PgLPS1690 significantly upregulated the secretion of pro-inflammatory cytokines IL-1 $\beta$, IL-6, IL- 8 and TNF- $\alpha$ in RHGE compared to tetraacylated PgLPS1435. It seemed that regulation of proinflammatory cytokine by PgLPS1690 is mediated through both TLR2 and 4 and CD14/NF-kB axis for most of the

${ }^{1}$ The University of Hong Kong, Hong Kong SAR

Full list of author information is available at the end of the article cytokines. Proteomic studies indicated a differential protein profiles of RHGE induced with two isoforms.

\section{Conclusion}

P. gingivalis LPS heterogeneity differentially modulates the host innate immune response in human gingival epithelium, which may explain the niche-specific pathogenic mechanism of this periodontal pathogen.

\section{Acknowledgements}

Supported by grants GRF 7518/05M and GRF HKU766909M to LJJ.

\section{Author details}

${ }^{1}$ The University of Hong Kong, Hong Kong SAR. ${ }^{2}$ University of Washington, Seattle, USA. ${ }^{3}$ UCLA School of Dentistry, Los Angeles, USA.

Published: 10 January 2011

doi:10.1186/1753-6561-5-S1-P86

Cite this article as: Herath et al:: Heterogeneous LPS of Porphyromonas gingivalis differentially modulate the innate immune response of human gingiva. BMC Proceedings 2011 5(Suppl 1):P86.

Submit your next manuscript to BioMed Central and take full advantage of:

- Convenient online submission

- Thorough peer review

- No space constraints or color figure charges

- Immediate publication on acceptance

- Inclusion in PubMed, CAS, Scopus and Google Scholar

- Research which is freely available for redistribution 